\title{
Dynamic Brazilian Tests of Granite Under Coupled Static and Dynamic Loads
}

\author{
Zilong Zhou $\cdot$ Xibing Li $\cdot$ Yang Zou $\cdot$ \\ Yihui Jiang $\cdot$ Guonan Li
}

Received: 3 November 2012 / Accepted: 18 May 2013/Published online: 2 June 2013

(C) Springer-Verlag Wien 2013

\begin{abstract}
Rocks in underground projects at great depth, which are under high static stresses, may be subjected to dynamic disturbance at the same time. In our previous work (Li et al. Int J Rock Mech Min Sci 45(5):739-748, 2008), the dynamic compressive behaviour of pre-stressed rocks was investigated using coupled-load equipment. The current work is devoted to the investigation of the dynamic tensile behaviour of granite rocks under coupled loads using the Brazilian disc (BD) method with the aid of a high-speed camera. Through wave analyses, stress measurements and crack photography, the fundamental problems of BD tests, such as stress equilibrium and crack initiation, were investigated by the consideration of different loading stresses with abruptly or slowly rising stress waves. The specially shaped striker method was used for the coupled-load test; this generates a slowly rising stress wave, which allows gradual stress accumulation in the specimen, whilst maintaining the load at both ends of the specimen in an equilibrium state. The test results showed that the tensile strength of the granite under coupled loads decreases with increases in the static pre-stresses, which might lead to modifications of the blasting design or support design in deep underground projects. Furthermore, the failure patterns of specimens under coupled loads have been investigated.
\end{abstract}

Z. Zhou $(\bowtie) \cdot$ X. Li · Y. Jiang · G. Li

School of Resources and Safety Engineering,

Central South University, Changsha 410083, Hunan,

People's Republic of China

e-mail: zlzhou@mail.csu.edu.cn

Y. Zou

School of Architecture, Civil and Environmental Engineering,

École Polytechnique Fédérale de Lausanne (EPFL),

1015 Lausanne, Switzerland
Keywords Brazilian test - Tensile strength · Coupled loads · Crack initiation · Stress equilibrium · High-speed photography

$\begin{array}{ll}\text { Abbreviations } \\ \text { BD } & \text { Brazilian disc } \\ \text { SHPB } & \text { Split Hopkinson pressure bar } \\ \text { P-wave } & \text { Longitudinal wave } \\ \text { S-wave } & \text { Shear wave }\end{array}$

\section{List of symbols}

$\alpha \quad$ Incident angle $\left({ }^{\circ}\right)$

$l \quad$ Travelling distance of the stress wave $(\mathrm{m})$

$C_{d} \quad$ P-wave velocity $(\mathrm{m} / \mathrm{s})$

$R \quad$ Radius of the specimen (m)

$t \quad$ Travelling time of the stress wave (s)

$\sigma_{\mathrm{t}}$ Dynamic tensile strength of the specimen (MPa)

$\sigma_{\mathrm{c}}$ Dynamic compressive strength of the specimen (MPa)

$\sigma_{0} \quad$ Amplitude of the assumed stress pulse (MPa)

$P \quad$ Static force applied on the specimen (N)

$P_{\mathrm{c}}$ Equivalent force applied on the specimen under coupled loads $(\mathrm{N})$

$T \quad$ Thickness of the specimen (m)

$\pi \quad$ Circular constant

\section{Introduction}

In mining and other underground excavations at great depth, rocks are subjected to high static and dynamic loads simultaneously, which we call coupled loads. Static loads can be gravity stress or tectonic stress, and dynamic loads may be from drilling, blasting or earthquakes. Rock under such static-dynamic coupled loads might have completely different behaviour to that under only static or dynamic 
loads. Using in-house developed coupled-load equipment, the dynamic compressive behaviour of rock under different coupled loads was investigated in 2008 ( $\mathrm{Li}$ et al. 2008). With continuous improvement of the equipment, the coupled-load equipment can be used for the Brazilian test for obtaining the tensile strength of rock under coupled loads.

The Brazilian test is a popular method for studying the tensile characteristics of materials, but it is mainly used for static tests. Since Hertz proposed the theoretical expression describing the stress states of circular discs under diametrical point loads (Hondros 1959), the Brazilian test has been greatly developed. It has been applied to weak rock like coal to hard rock like granite (Fairhurst 1964; Mellor and Hawkes 1971; Hudson et al. 1972; Pomeroy and Morgans 1956) and isotropic to anisotropic rock (Barla and Innaurato 1973; Berenbaum and Brodie 1959; Cai and Kaiser 2004; Claesson and Bohloli 2002; Wang et al. 2004). Due to the easy preparation of specimens and simple test operation, the static Brazilian test is a method suggested by the International Society for Rock Mechanics (ISRM) (Bieniawski and Hawkes 1978).

Recently, the Brazilian test has been extended to dynamic tests. Zhao and $\mathrm{Li}$ (2000) investigated the dynamic tensile properties of granite with Brazilian disc (BD) specimens. The tests were conducted on a self-built air- and oil-driven machine. Wang et al. (2006) carried out dynamic BD tests on a split Hopkinson pressure bar (SHPB) with a flattened BD specimen. We also used Brazilian tests on an SHPB to investigate the tensile strength of granite at different loading rates (Zhou et al. 2007). Dai and Xia (2010) further studied the loading rate dependence of the tensile strength of anisotropic rock with a BD specimen on an SHPB. All these researches show the feasibility of Brazilian testing on an SHPB in determining the dynamic tensile strength of rock materials. In 2012, Brazilian testing on an SHPB was suggested as the ISRM test method (Zhou et al. 2012).

In this paper, the Brazilian test was used to investigate the coupled-load properties of rock. Some basic problems like crack initiation and stress equilibrium in the disc specimens have been clarified and experimentally verified. The dynamic tensile strength of granite specimens under different coupled loads has been investigated and the failure patterns of the specimens are discussed.

\section{Test Preparation}

\subsection{Specimen Preparation}

Tests were performed on specimens extracted from a single granite block with good geometrical integrity and petrographic uniformity. Special care was taken to prepare cylindrical specimens with a diameter of $50 \mathrm{~mm}$ and a length/diameter ratio of 0.5 . All specimens were polished to have a surface roughness of $<0.02 \mathrm{~mm}$ and end surface perpendicularity to the specimen axis with a tolerance of $<0.001 \mathrm{rad}$ (Zhou et al. 2012).

The specimens were labelled after preparation and their names reflected the sequence of coring and cutting. For example, "G13-5" indicates that this specimen is a granite specimen obtained from the fifth sample of core 13 .

\subsection{Test Apparatus and Scheme}

The tests were conducted on the coupled-load equipment described by Li et al. (2008). The specimen is sandwiched between two cylindrical elastic bars during the tests. The elastic bars are made of steel with a density of 7,800 $\mathrm{kg} \mathrm{m}^{-3}$ and an elastic modulus of $250 \mathrm{GPa}$. Static pre-stresses are applied by the pressure-loading unit through elastic bars. Dynamic loading comes from the impact of a striker driven by high-pressure gas. The failure process of the specimen is monitored by a high-speed camera (FASTCAM SA1.1). The stress histories of the specimens are captured by strain gauges $(2 \times 1 \mathrm{~mm})$ mounted on the elastic bars and specimen surfaces. The data processing unit includes a CS-1D super dynamic strain meter (Beidaihe), a computer and a DL750 ScopeCorder Digital Oscilloscope (Yokogawa).

During the tests, the axial pre-stresses are changed by the static stress loading unit, and the impact loads on the specimens are offered by a striker whose velocity is controlled by regulating the air pressure in the gas vessel. Theoretically, both stresses could be high enough for the steel frame of the equipment to yield. However, in practice, they should be chosen properly so that static pre-stresses do not cause specimen failure before the specimen reaches stress equilibrium.

Before the coupled-load tests, static Brazilian tests with static loads only were carried out to obtain the average static tensile strength for choosing proper pre-stresses in the coupled-load tests.

The static BD tests were conducted on an Instron (1342) system. Specimens were put directly between the platens (ASTM International 2008). The loading rate was very low, resulting in a displacement rate not exceeding $0.01 \mathrm{~mm} /$ min. The static tensile strength of the specimen was calculated by:

$\sigma_{f}=\frac{P}{\pi R T}$

where $P$ is the static force applied on the specimen, $\pi$ is a circular constant, and $R$ and $T$ are the radius and thickness of the specimen, respectively.

The contact states of the platen and the specimen in the BD tests is a factor that has been researched intensively in 
the past (Markides and Kourkoulis 2013; Li and Wong 2013). Specially designed jaws are usually used in static BD tests (ISRM 1978). According to some works, failure may initiate directly under the loading points if the jaws are not used, leading to underestimation of the tensile strength (Fairhurst 1964; Hudson et al. 1972). But recently, more and more theoretical and numerical analyses have shown that the exact boundary conditions at the disc's periphery do not play any crucial role in the results of the Brazilian test (Markides and Kourkoulis 2012, 2013; Markides et al. 2010, 2012).

Friction is another factor that may lead to discrepancy between the experimental results and the true strength. As friction is very difficult to determine experimentally, there are few quantitative results concerning its influence on BD tests. Recently, theoretical and numerical results indicate that friction between the platen and the specimen can affect the stress distribution in the immediate vicinity of the contact rim. But the stress field at the disc's centre is totally insensitive to the exact distribution of radial pressure and also to the presence or absence of friction (Lavrov and Vervoort 2002; Lanaro et al. 2009; Markides et al. 2010, 2011; Markides and Kourkoulis 2013). Thus, the specimens were placed directly between the loading platens and friction was ignored. Of course, the central crack initiation of the disc was carefully checked in each test.

With static BD tests, the granite's average static tensile strength was obtained as $9.89 \mathrm{MPa}$, as shown in Table 1 . Accordingly, the static pre-stresses were chosen to be 0 , 3.6, 5.4, 7.2 and 9.0 MPa to begin with. But in practice, when the specimen was loaded by the coupled-load equipment with axial pre-stresses of $9.0 \mathrm{MPa}$, it tended to fail before the impact. The reason for this may lie in the fact that the stiffness of the elastic bars of the coupled-load equipment is smaller than that of the Instron system. When the axial pre-stress reaches $9.0 \mathrm{MPa}$, the specimen may reach or exceed its yield point. Then, the stability of the system and the specimen decreases, which has been previously observed in compressive tests of rock under coupled loads ( $\mathrm{Li}$ et al. 2008). Therefore, the static pre-stresses

Table 1 Parameters and test results of specimens under static load only

\begin{tabular}{lllllc}
\hline Specimen no. & $\begin{array}{l}\text { Diameter } \\
(\mathrm{mm})\end{array}$ & $\begin{array}{l}\text { Length } \\
(\mathrm{mm})\end{array}$ & $\begin{array}{l}\text { Density } \\
\left(\mathrm{kg} \mathrm{m}^{-3}\right)\end{array}$ & $\begin{array}{l}\text { Wave } \\
\text { velocity } \\
(\mathrm{m} / \mathrm{s})\end{array}$ & $\begin{array}{l}\text { Tensile } \\
\text { strength } \\
(\mathrm{MPa})\end{array}$ \\
\hline G10-1 & 49.02 & 24.88 & $2,663.37$ & $4,442.86$ & 9.19 \\
G10-2 & 49.02 & 25.36 & $2,654.96$ & $4,449.12$ & 10.14 \\
G14-3 & 49.04 & 25.30 & $2,648.43$ & $4,438.60$ & 9.80 \\
G14-4 & 49.00 & 25.40 & $2,649.39$ & $4,535.71$ & 10.42 \\
Average & & & & & 9.89 \\
\hline
\end{tabular}

were finally chosen to be $0,3.6,5.4$ and $7.2 \mathrm{MPa}$ for the coupled-load tests in this paper.

With the coupled-load equipment, the dynamic loads are controlled by a gas gun with high-pressure nitrogen gas. With the commonly available nitrogen gas tank in the laboratory, impact loads with peak values of 150 and $250 \mathrm{MPa}$ were used for the tests. In each load set, four specimens were tested, and the details of the specimen parameters and loads are shown in Table 2.

\section{Crack Initiation and Stress Equilibrium of Specimens Under Different Stress Waves}

Stress equilibrium and central crack initiation are basic requirements for an eligible static Brazilian test. When an elastic BD specimen is loaded by a diametrical static force, its stress will reach equilibrium automatically and axi-symmetrically. With the stresses at the disc centre satisfying the Griffith criterion, the crack would initiate (Bieniawski and Hawkes 1978; Li et al. 2008; Wang et al. 2004). Then, the specimen's tensile strength can be determined theoretically (Hondros 1959). However, when the BD specimen is subjected to dynamic loads of changing magnitude and time duration, there is no automatic stress equilibrium as in the static case. The crack initiation and failure process would be controlled by a more complex stress distribution which changes in time and space simultaneously (Zhu and Tang 2006). That is, the stress equilibrium of the BD specimen under static loads is only in the spatial field, but specimens under dynamic loads will experience not only spatial non-uniformity, but also time non-uniformity. The wave profile and duration of the loading stress will play a key role in controlling the test results. In a traditional SHPB-type system, the rectangular wave generated by a cylindrical striker is commonly used as the loading stress. This type of loading method has been proved unfit for dynamic rock tests (Frew et al. 2002; Li et al. 2011). In our coupled load equipment, a slowly rising wave generated by a specially shaped striker is adopted. Its feasibility for the coupled-load tests should be justified first. Thus, the dynamic response of the specimen under different stress waves, especially the stress wave from the specially shaped striker, is analysed. The crucial problems of stress equilibrium and crack initiation of the specimen are investigated.

\subsection{Dynamic Response of Specimens Under Stress Pulses or Abruptly Rising Stress Waves}

The biggest difference between the static and dynamic loads is the time effect. When a static load is applied to an object, the stress distribution takes shape immediately and 
Table 2 Parameters and test results of specimens under coupled loads

\begin{tabular}{|c|c|c|c|c|c|c|c|}
\hline $\begin{array}{l}\text { Peak impact } \\
\text { stress (MPa) }\end{array}$ & $\begin{array}{l}\text { Axial static } \\
\text { pre-stress }(\mathrm{MPa})\end{array}$ & Specimen no. & $\begin{array}{l}\text { Diameter } \\
(\mathrm{mm})\end{array}$ & $\begin{array}{l}\text { Length } \\
(\mathrm{mm})\end{array}$ & $\begin{array}{l}\text { Density } \\
\left(\mathrm{kg} \mathrm{m}^{-3}\right)\end{array}$ & $\begin{array}{l}\text { Wave velocity } \\
(\mathrm{m} / \mathrm{s})\end{array}$ & $\begin{array}{l}\text { Central crack } \\
\text { initiation }\end{array}$ \\
\hline \multirow[t]{16}{*}{150} & \multirow[t]{4}{*}{0} & G13-5 & 49.02 & 25.00 & $2,652.28$ & $4,310.35$ & Yes \\
\hline & & G7-4 & 49.02 & 24.72 & $2,648.03$ & $4,336.84$ & Yes \\
\hline & & G4-4 & 49.02 & 25.10 & $2,644.67$ & $4,403.51$ & Yes \\
\hline & & $\mathrm{G} 2-4$ & 49.02 & 25.16 & $2,647.62$ & $4,414.03$ & Yes \\
\hline & \multirow[t]{4}{*}{3.6} & G9-3 & 49.02 & 24.80 & $2,664.06$ & $4,428.57$ & Yes \\
\hline & & G1-5 & 49.02 & 24.72 & $2,655.95$ & $4,336.84$ & No \\
\hline & & G14-2 & 49.12 & 24.82 & $2,624.23$ & $4,432.14$ & Yes \\
\hline & & G3-3 & 49.20 & 24.32 & $2,652.03$ & $4,342.86$ & Yes \\
\hline & \multirow[t]{4}{*}{5.4} & G3-5 & 49.02 & 25.38 & $2,670.82$ & $4,452.63$ & Yes \\
\hline & & G13-3 & 49.02 & 25.40 & $2,655.36$ & $4,456.14$ & Yes \\
\hline & & G11-3 & 48.98 & 25.20 & $2,650.70$ & $4,344.83$ & Yes \\
\hline & & G8-1 & 49.18 & 24.82 & $2,656.28$ & $4,354.39$ & Yes \\
\hline & \multirow[t]{4}{*}{7.2} & G6-4 & 49.02 & 25.40 & $2,660.20$ & $4,456.14$ & No \\
\hline & & G1-2 & 49.02 & 25.42 & $2,635.14$ & $4,459.65$ & Yes \\
\hline & & G8-4 & 49.40 & 25.26 & $2,659.32$ & $4,355.17$ & Yes \\
\hline & & G1-1 & 49.38 & 24.90 & $2,641.44$ & $4,368.42$ & Yes \\
\hline \multirow[t]{16}{*}{250} & \multirow[t]{4}{*}{0} & G8-3 & 49.42 & 25.20 & $2,635.56$ & $4,490.56$ & Yes \\
\hline & & G4-3 & 49.02 & 24.92 & $2,639.32$ & $4,371.93$ & Yes \\
\hline & & G11-2 & 48.98 & 24.94 & $2,656.41$ & $4,375.44$ & Yes \\
\hline & & G7-3 & 49.02 & 24.62 & $2,667.82$ & $4,476.36$ & Yes \\
\hline & \multirow[t]{4}{*}{3.6} & G6-5 & 49.02 & 25.20 & $2,645.22$ & $4,500.0$ & Yes \\
\hline & & G5-5 & 49.02 & 25.20 & $2,636.68$ & $4,500.0$ & No \\
\hline & & G4-2 & 49.02 & 24.78 & $2,644.82$ & $4,425.0$ & Yes \\
\hline & & G2-1 & 49.02 & 25.02 & $2,641.06$ & $4,389.47$ & Yes \\
\hline & \multirow[t]{4}{*}{5.4} & G5-2 & 49.02 & 25.20 & $2,645.53$ & $4,500.0$ & Yes \\
\hline & & G3-2 & 49.02 & 25.20 & $2,665.93$ & $4,500.0$ & Yes \\
\hline & & G6-1 & 48.94 & 25.30 & $2,653.36$ & $4,517.86$ & Yes \\
\hline & & G12-5 & 49.24 & 25.10 & $2,637.20$ & $4,403.51$ & Yes \\
\hline & \multirow[t]{4}{*}{7.2} & G5-4 & 48.94 & 25.32 & $2,647.28$ & $4,521.43$ & Yes \\
\hline & & G9-2 & 49.02 & 25.00 & $2,659.06$ & $4,629.63$ & Yes \\
\hline & & G7-2 & 49.02 & 25.02 & $2,646.35$ & $4,633.33$ & Yes \\
\hline & & G10-4 & 49.48 & 25.10 & $2,642.35$ & $4,403.51$ & Yes \\
\hline
\end{tabular}

remains unchanged. However, when a dynamic load with limited duration is applied, the stress distribution in the specimen changes with time corresponding to the external load. In order to obtain some general insight into the dynamic response of the BD specimen under dynamic loads, a fictional compressive stress pulse with infinitesimal duration is assumed to transmit into the BD specimen. The wave propagation and wave interaction in a specimen loaded by a pulse stress can be described by Fig. 1. Strictly, when a compressive $\mathrm{P}$-wave is reflected at a free surface, a tensile $\mathrm{P}$-wave and shear $\mathrm{S}$-wave will arise. When the $\mathrm{S}$-wave reaches the specimen boundary, more of the $\mathrm{P}$-wave and S-wave will be reflected. These reflected pulse components will share the amplitude and energy of the incident stress pulse (Rinehart 1975). So, the reflection of stress waves will lead to a great loss of amplitude and energy. And, for rock materials, the velocity of the P-wave is about twice that of the S-wave. Additionally, rocks are more sensitive to tensile failure than shear failure, and, therefore, the $\mathrm{S}$-waves are neglected for the theoretical analyses here.

As sketched in Fig. 1, the pulse with a bigger incident angle reaches the specimen boundary earlier but there will be more reflections at the specimen boundary before it reaches the diametrical line $\mathrm{AB}$. As reflections can lead to amplitude/energy loss of stress pulses, the more reflections there are, the more stress amplitude/energy loss there is. Thus, only those pulses with incident angles $0^{\circ}<\alpha<45^{\circ}$, 




Fig. 1 Propagation of stress pulse and its interaction with the specimen boundary

which have one reflection, will carry high-level tensile stress and reach line $\mathrm{OB}$, where the superimposition of tensile stresses from both sides further increases the tensile stress there.

For a specific impulse approaching E through D with incident angle $\alpha$, its travelling time and arrival location on the diametrical line can be determined as:

$t=l_{(\mathrm{AD}+\mathrm{DE})} / C_{d}=(2 R \cos \alpha+R \sin 2 \alpha / \sin 3 \alpha) / C_{d}$

$l_{\mathrm{OE}}=R \sin \alpha / \sin 3 \alpha$

where $l$ is the travelling distance of the stress wave, $C_{d}$ is the $\mathrm{P}$-wave velocity of the specimen and $R$ is the radius of the $\mathrm{BD}$ specimen.

As can be seen from Fig. 2, with the increase of the incident angles, the arrival location of the reflected pulse will be further away from the specimen centre. However, the travel time does not increase linearly with the increase of the incident angle. The stress pulse with an incident angle of $30^{\circ}$ reaches the diametrical line earliest, at the point located at $0.5 R$ from the specimen centre.

Based on the above analyses, the crack initiation of BD specimens under a stress pulse can be deduced. Assuming that a specimen with dynamic tensile strength $\sigma_{\mathrm{t}}$ and dynamic compressive strength $\sigma_{\mathrm{c}}$ is loaded by a stress pulse with an amplitude of $\sigma_{0}$, then the possibilities regarding specimen failure are as follows: (a) The pulse amplitude $\sigma_{0}$ is so strong that it exceeds the material compressive strength $\sigma_{\mathrm{c}}$. In this situation, the contact zone between the loading device and specimen boundary will fail immediately once the stress pulse propagates into it. (b) The pulse amplitude $\sigma_{0}$ is lower than the compressive strength $\sigma_{\mathrm{c}}$. It will travel to the specimen boundary, be reflected, and

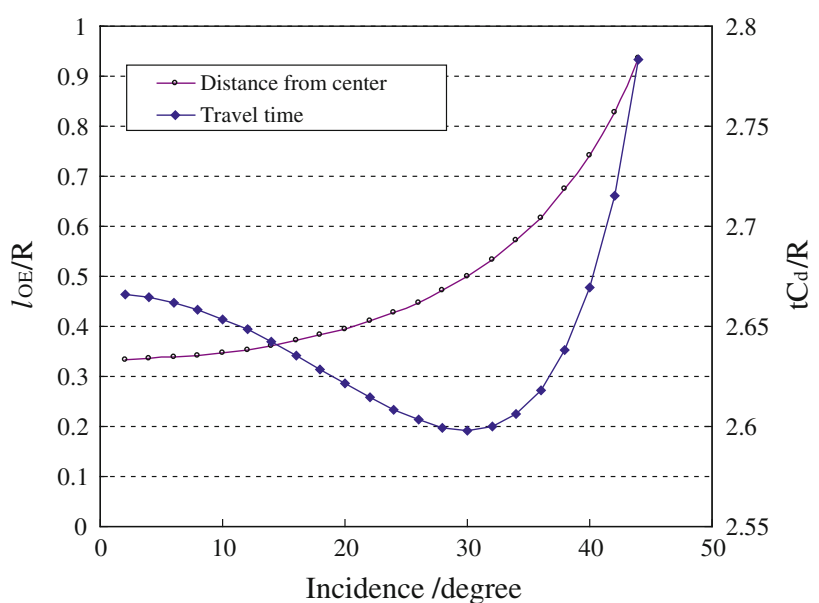

Fig. 2 Travel time and possible location of the first crack

reach the diametrical line. As the point $0.5 R$ from the specimen centre is the place where the high-level tensile stress emerges first, if the tensile stress there surpasses the material tensile strength $\sigma_{\mathrm{t}}$, the crack will initiate there first. Therefore, when the disc specimen is loaded by stress pulses, the point $0.5 R$ from the specimen centre at the opposite end to the load could be the place which is the most vulnerable to failure.

Meanwhile, the above theoretical analyses also reveal that a rectangular wave with an abruptly rising front in the traditional SHPB setup is unfit for tests of brittle materials (Li et al. 2011). The rectangular wave, with an abruptly rising front, is actually a stress pulse with limited time duration. Except for the premature failure near the contact zone and the non-central initiation of tensile cracking, the rich frequency components of a rectangular wave may lead to dispersion effects, which also make it inappropriate for SHPB-type tests of rock materials ( $\mathrm{Li}$ et al. 2009).

\subsection{Stress Evolution of Specimens Under Slowly Rising Stress Waves}

The shortcomings of abruptly rising stress waves for SHPB tests of brittle materials were realised years ago and many improvements have been made in order to solve these problems. One good effort was realised by the pulse shaper method (Frantz et al. 1984; Frew et al. 2002), where a thin sheet of paper, aluminium, copper or steel was placed between the striker and the input bar of the SHPB device to produce a slowly rising stress wave. Another successful attempt was conducted through the fabrication of specially shaped strikers (Li et al. 2009, 2011; Zhou et al. 2010, 2011a, b), which produced approximately a half-sine wave. Both of these methods can avoid the premature failure of specimens in tests. Furthermore, the analysis in Sect. 3.1 shows that a stress wave with an abrupt front cannot ensure 


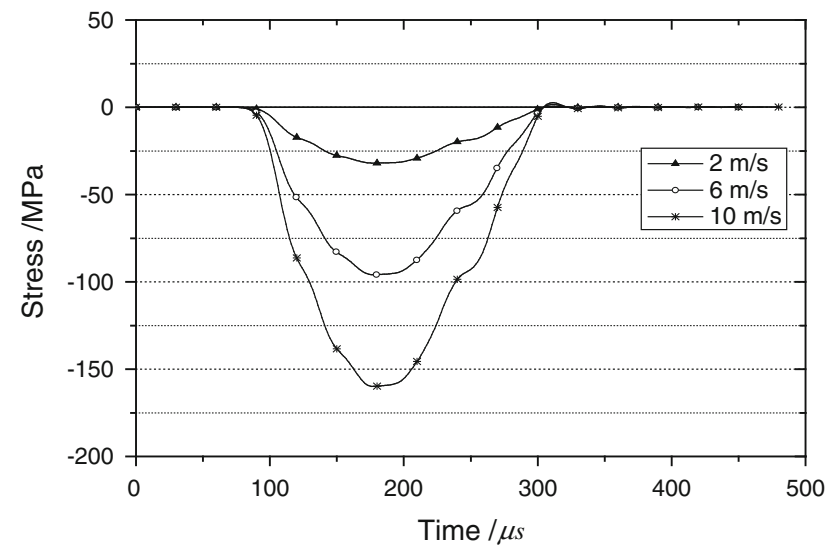

Fig. 3 Stress waves generated by the specially shaped striker with different velocities



Fig. 4 Signals captured from the strain gauges on the SHPB bars

that the specimen will break from its centre. However, with a slowly rising stress wave, the relatively small amplitude at the onset of the incident wave will offer enough time for the specimen to reach stress equilibrium. Then, the first crack might initiate from the specimen centre.

In the following tests, the specially shaped striker method was used to generate slowly rising stress waves and to examine the stress equilibrium and crack initiation of specimens. The geometrical parameters of the striker can be found in Fig. 1a of our previous work (Zhou et al. 2011b). Figure 3 shows the stress waves it generates for different impact velocities.

Initially, Brazilian tests with only dynamic loading were conducted. After careful calibration of the test system (Zhou et al. 2011a), specimens were placed between the input and output bars and the striker was fired. Upon impingement of the input bar by the striker, the incident wave was generated and propagated along the input bar. At the interfaces of the specimen and steel bars, waves were

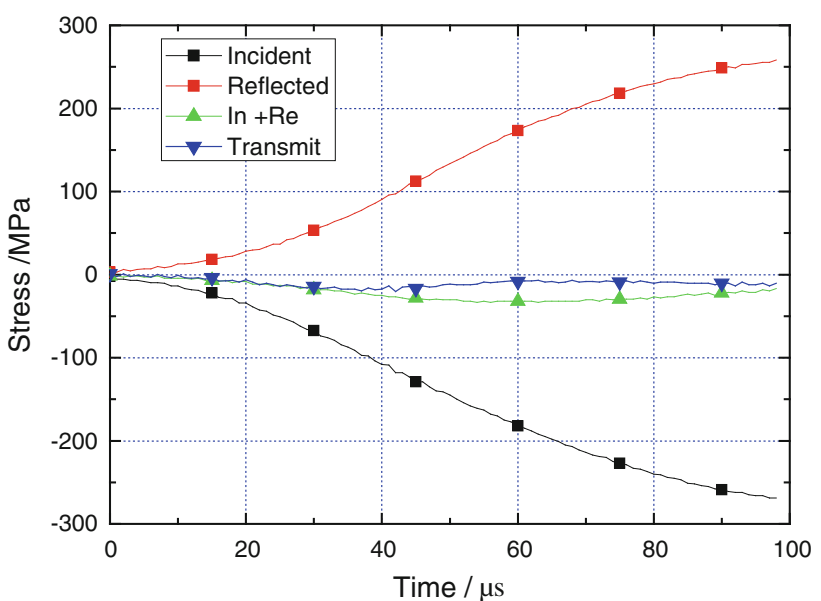

Fig. 5 Stress histories from the SHPB bars

(a)
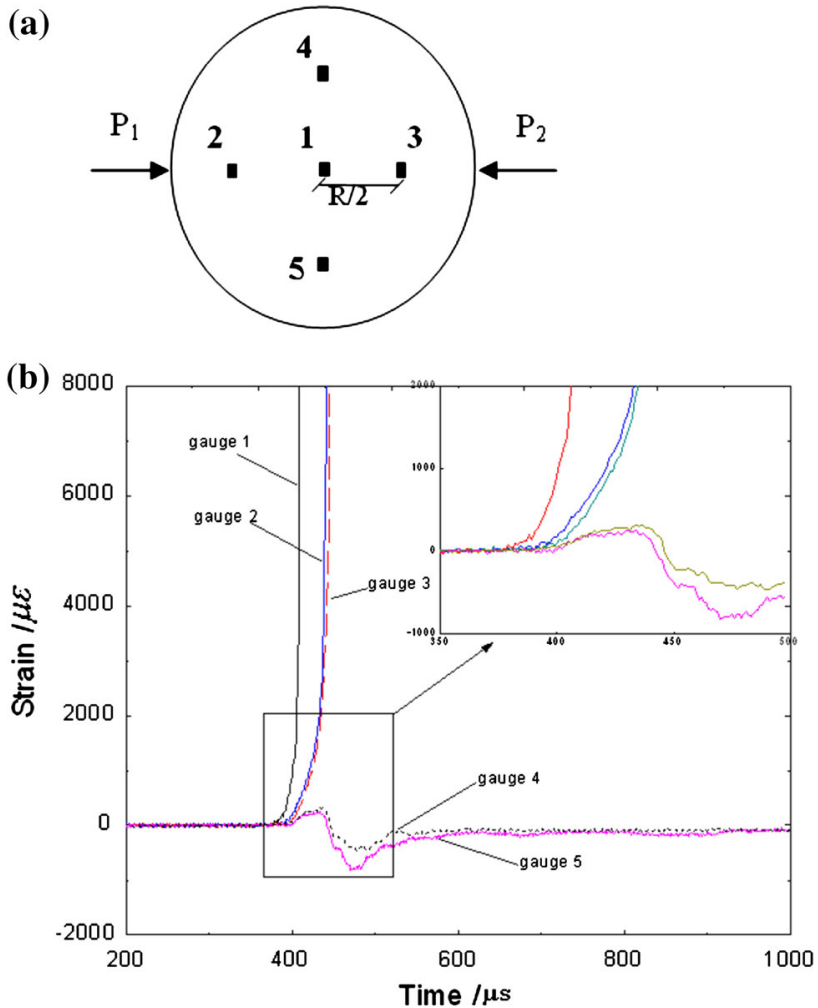

Fig. 6 Deformation information of the specimen obtained by strain gauges on its surface: a strain gauges on the specimen surface, b signals captured by the strain gauges

reflected and transmitted. The reflected wave, together with the incident wave, was captured by the strain gauge on the input bar and the transmitted wave was captured by the strain gauge on the output bar. Figure 4 shows the signals captured from the input/output bars when the impact velocity of the striker is $15 \mathrm{~m} / \mathrm{s}$. Here, the stresses are presented with voltage information captured directly by the strain gauges. The stress results illustrated in Fig. 5 further 



Fig. 7 Results of the trial test on specimens under coupled loads: a stress histories of strain gauges on the specimen surface, $\mathbf{b}$ stresses from elastic bars

show that the sum of the incident stress and reflected stress is equal to the transmitted stress before the transmitted wave reached its peak value. According to SHPB principles, this indicates that the stresses at both ends of the specimen remained in equilibrium before failure.

At the same time, strain gauges on the specimen's surface gave more details of the stress evolution of the specimen. Figure 6a shows the layout of the strain gauges on the specimen's surface. The direction of the fence length of the strain gauge is perpendicular to the load direction. Figure $6 \mathrm{~b}$ shows the deformation information obtained from these strain gauges. The signal from strain gauge 1 shows that the stress at the specimen centre increased faster from the other gauges and, also, that the strain gauge broke at $415 \mu \mathrm{s}$. This indicates that the central crack initiated at this moment. The signals from gauges 2 and 3 almost coincided with each other until these two strain gauges broke at $450 \mu \mathrm{s}$. This means that there was good stress equilibrium in the specimen before its failure. The stresses at the points of strain gauges 4 and 5 coincided with each other before $450 \mu \mathrm{s}$. This further reveals that the stress symmetry and force balance in the specimen were maintained very well.
3.3 Stress Equilibrium and Crack Initiation of Specimens Under Coupled Loads

Because of the importance of stress equilibrium and crack initiation for Brazilian tests, they were also checked before the large-scale experiments on rocks with coupled static and dynamic loads. Figure 7 gives the signal results captured from a specimen which was subjected to static prestress of 5.4 MPa and an impact load with a peak value of $180 \mathrm{MPa}$.

The signals in Fig. 7a clearly show the failure process of the specimen. For strain gauge 1 at the specimen centre, failure occurred earlier with a sudden increase of the tensile stress at $415 \mu \mathrm{s}$, which denotes the central crack initiation. Then, the other two strain gauges 2 and 3 released their compressive stresses, which meant that the crack propagated through them. Compared with Fig. 6b, it can be seen that the specimen with static pre-stresses experienced a deformation process different from that of the specimen with an exclusively dynamic load. Strain gauges 2 and 3 in Fig. 7a initially experienced a compressive state; then, gauge 2, nearer to the loading end, released the stress more violently than the right-hand gauge at $430 \mu$ s. Gauges 2 and 3 in Fig. $6 \mathrm{~b}$ experienced only tensile deformation and failed at almost the same time. This may have been caused by the pre-existing load in the specimen.

Even though gauges 2 and 3 in Fig. 7a had the same stress histories before $440 \mu \mathrm{s}, 25 \mu \mathrm{s}$ after the initiation of the central crack, in Fig. $7 \mathrm{~b}$, the stresses measured from the elastic bars show that the sum of the incident stress and the reflected stress had a long period of accordance with the transmitted stress measured from the SHPB bars. This also indicates the stress equilibrium of the specimen during crack propagation. In addition, the high-speed camera photography in Fig. 8 shows that $25 \mu$ s is long enough for the initial crack to propagate from the specimen centre to the boundary. Therefore, the specimen almost maintained stress symmetry and equilibrium during the whole process of crack propagation.

\section{Tensile Strength of Rock Under Coupled Loads}

Previous researches (Lanaro et al. 2009; Markides et al. 2010, 2011; Markides and Kourkoulis 2013; Dai et al. 2010; Zhou et al. 2012) on static and dynamic BD tests have all shown that the BD test can give accurate strength results once the following conditions are met: (1) the stress/ force equilibrium should be satisfied before the specimen fails and (2) the crack should initiate from the disc centre and propagate along the loading direction diametrically. In dynamic BD tests, the stress field of the specimen under dynamic loads is similar to that of the specimen under 
Fig. 8 Failure process of the specimen in the trial test (with strain gauges on the back surface)
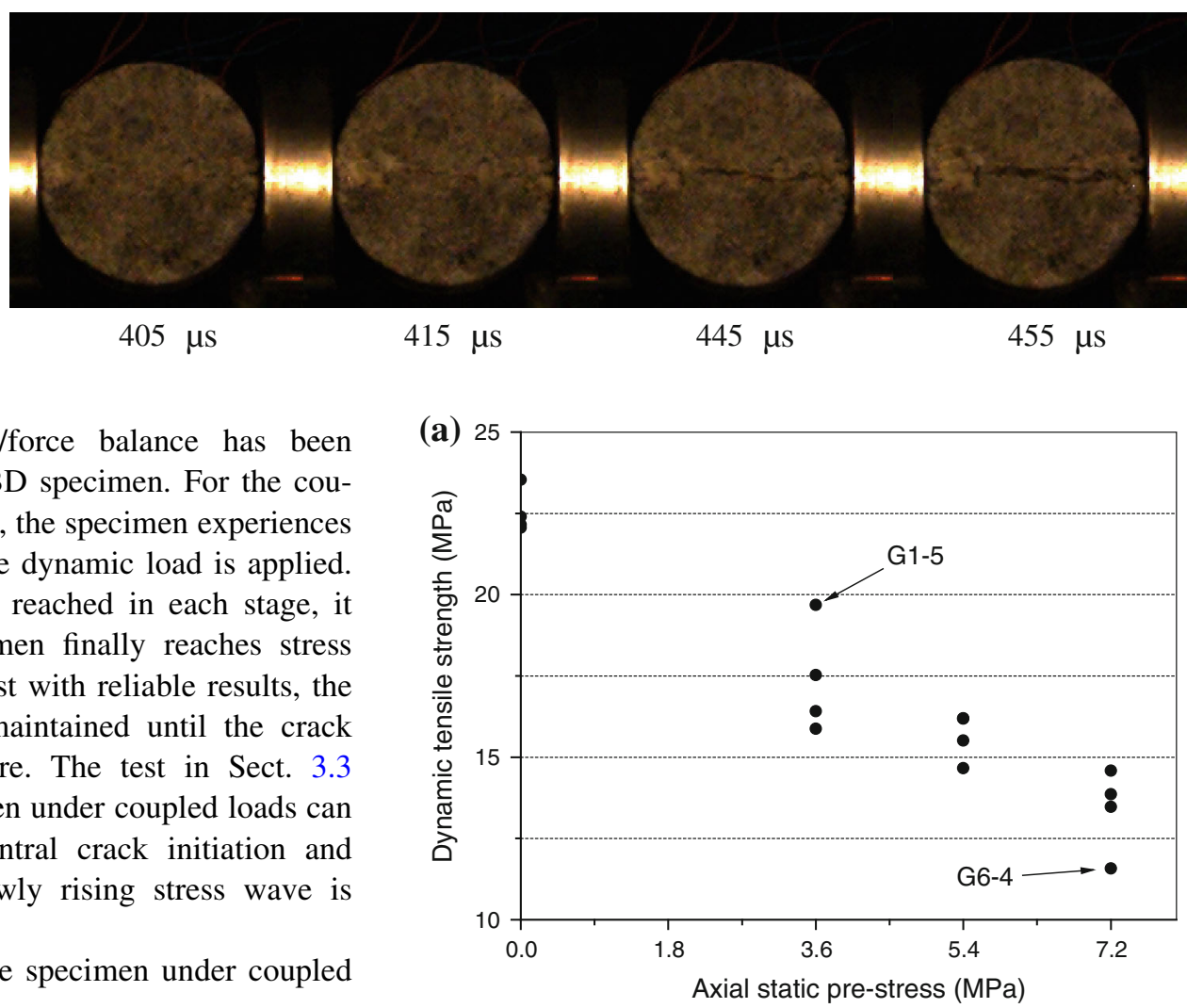

static loads, when the stress/force balance has been achieved on both ends of the BD specimen. For the coupled-load tests of the paper, first, the specimen experiences the static pre-stress and then the dynamic load is applied. When the stress equilibrium is reached in each stage, it should be said that the specimen finally reaches stress equilibrium. Of course, for a test with reliable results, the stress equilibrium should be maintained until the crack starts from the specimen centre. The test in Sect. 3.3 already showed that the specimen under coupled loads can satisfy the prerequisites of central crack initiation and stress equilibrium when a slowly rising stress wave is applied.

So, the tensile strength of the specimen under coupled loads can be calculated by:

$\sigma_{f}=\frac{P_{\mathrm{c}}}{\pi R T}$

where $P_{\mathrm{c}}$ is the equivalent force applied on the specimen, $\pi$ is a circular constant, and $R$ and $T$ are the radius and thickness of the specimen, respectively.

The equivalent force is obtained from the stress information on the input and output bars of the SHPB (Zhou et al. 2012). It is necessary to note that one-dimensional stress wave theory is not strictly satisfied near the bar/ specimen contact area, and the stress may not be uniform at the bar ends. So, the position of the strain gauge on the SHPB bars should be carefully chosen to avoid the end effect (Zhou et al. 2011b).

After all the basic problems of BD tests under coupled loads had been analysed, granite specimens were tested. The load conditions and basic parameters of specimens in the coupled-load tests are listed in Table 2. As stress equilibrium plays a crucial role in BD tests relating to dynamic loads, only specimens satisfying the stress equilibrium are included. As there are failure pattern analyses in the paper, some specimens without central crack initiation have also been included.

Figure 9a shows the dynamic tensile strength of the specimens under different static pre-stresses and the same dynamic impact load with a peak value of $150 \mathrm{MPa}$. It can be seen that, when there is no static pre-stress, the dynamic tensile strength of granite is about $22 \mathrm{MPa}$, which is more



Fig. 9 Tensile strength of granite under different coupled loads: a under different static stresses and impact load of peak value $150 \mathrm{MPa}, \mathbf{b}$ under different static stresses and impact load of peak value $250 \mathrm{MPa}$

than twice its static tensile strength of $9.89 \mathrm{MPa}$. When the pre-stress is $3.6 \mathrm{MPa}$, the average dynamic tensile strength is $17.8 \mathrm{MPa}$. The result of specimen G1-5 is not included in the strength average, because central crack initiation was not satisfied. Instead of being discarded directly, the strength of G1-5 is also calculated by Eq. (4). It is found to have a value of $20 \mathrm{MPa}$, which is much higher than the 
average value of 17.8 MPa. Experimental investigation showed that three cracks appeared near the disc centre soon after the specimen reached stress equilibrium. More strength or energy is needed for the propagation of multiple cracks. This may be the reason for the strength increase of the experimental result. When the pre-stress is 5.4 and 7.2 $\mathrm{MPa}$, the average dynamic tensile strength is 15.6 and 13.9 MPa, respectively. Again, the result of specimen G6-4 is not included for the strength average. Specimen G6-4, with a strength of $11.6 \mathrm{MPa}$ calculated by Eq. (4), was found to have premature failure near the incident side, i.e. cracks appeared near the contact zone of the incident bar and specimen instead of the disc centre. The premature failure of the specimen undermines its overall strength greatly.

Figure $9 \mathrm{~b}$ presents the results for specimens under different static pre-stresses and the same dynamic impact load with a peak value of $250 \mathrm{MPa}$. When the pre-stresses are 0 , 3.6, 5.4 and $7.2 \mathrm{MPa}$, the average tensile strength results are 23.9, 19.8, 16.8 and $16.1 \mathrm{MPa}$, respectively. These values are all higher than those under the same static prestress and peak dynamic load of $150 \mathrm{MPa}$ in Fig. 9a. This strength increase effect on the loading rates is similar to that found by other dynamic tests (Zhou et al. 2007; Dai and Xia 2010). Specimen G5-5, without central crack initiation, is not included in the strength average. Its strength calculation by Eq. (4) gives a value of $17.6 \mathrm{MPa}$, which is much lower than the average value of 19.8 MPa. Experimental investigation also revealed the premature failure of the specimen near the incident side.

It should be emphasised that the strain meter was balanced after the pre-stress was applied. So, the dynamic tensile strength of specimens obtained above shows the coupled-load effect directly. According to the analyses of Fig. 9, when the impact load is constant, the tensile strength of granite under coupled loads gradually decreases with the increase in pre-stresses as a whole.

\section{Failure Pattern of Specimens}

The failure patterns of specimens can be an important indicator in revealing the failure mechanism of rocks. When high-speed camera images are unavailable, the failure pattern of the specimen is usually inferred by collecting the broken pieces of rock crumbs. For example, in the dynamic tests of granite by Zhou et al. (2007), the broken pieces of specimen were collected and their failure patterns were classified into three types. In the tests of this paper, the three types of failure patterns were also found by checking the broken pieces of specimens. Type I is a diametrical split. The specimen cracks at its centre and breaks neatly into two halves. When the two halves are put


Fig. 10 Failure pattern of specimens: a type I diametrical split, b type II central cracking with crushed wedges, $\mathbf{c}$ type III failure with crushed strap, $\mathbf{d}$ crack initiation of type III failure pattern 
Fig. 11 Process of formation of crushed wedges

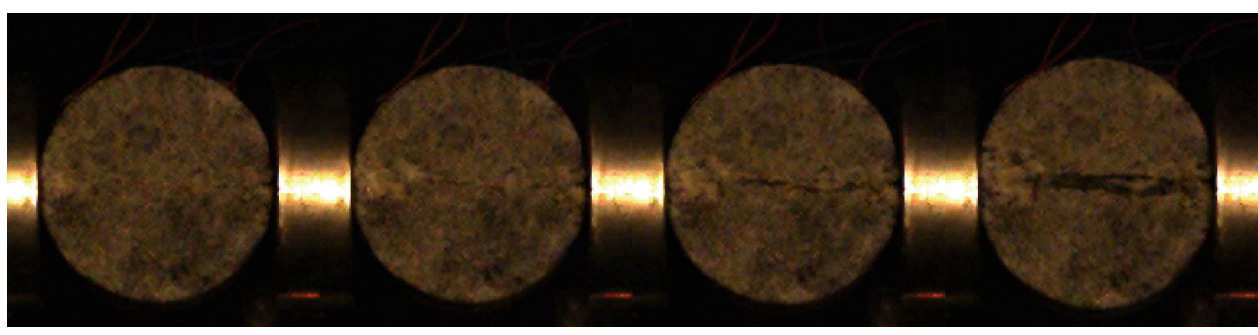

$405 \mu \mathrm{s}$

$415 \mu \mathrm{s}$

$445 \mu \mathrm{s}$

$655 \mu \mathrm{s}$

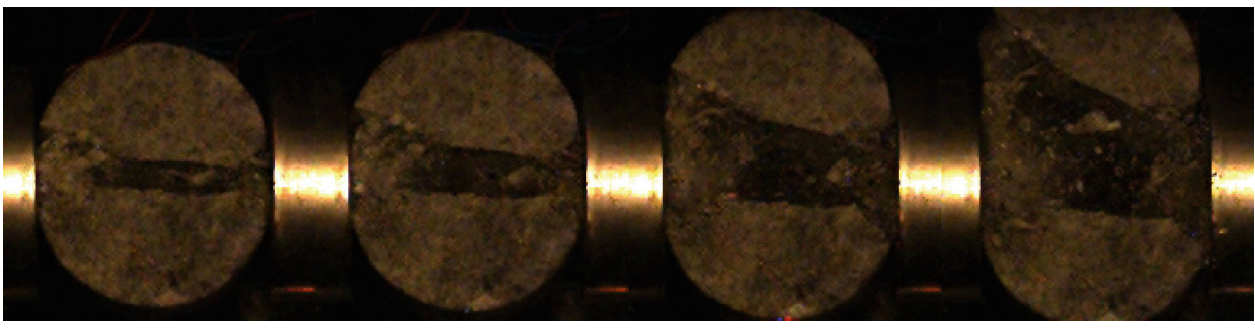

$955 \mu \mathrm{s}$

$1255 \mu \mathrm{s}$

$1855 \mu \mathrm{s}$

$2855 \mu \mathrm{s}$ together, they can recover the original shape of specimen, as shown in Fig. 10a. Type II has central cracking with crushed wedges. In this case, the specimen fails along its central line but small wedge-shaped pieces can be found in the crumbs, as shown in Fig. 10b. Type III shows failure with a crushed strap. In this case, a diametrically distributed crushed zone can be found in the specimen centre, as illustrated in Fig. 10c.

By analysing the camera pictures of specimen failure, new information is revealed. Regarding the type II failure pattern, it is found that this pattern should actually be classified as type I. Figure 11 presents some picture sequences of this type of failure. The specimen's first crack initiation occurred at $415 \mu$ s and it splits completely at $445 \mu$ s. Until this time, the failure pattern of the specimen was the same as in Fig. 10a. Even at $655 \mu$ s, the broken specimen still had two perfect halves. However, as time progressed, the two halves of the specimen moved apart and became fragile under the pushing force from the steel bars. Then, the corners of the specimen halves failed, breaking into wedge-shaped pieces by bending and shearing.

High-speed camera photography showed that type III failure patterns usually appeared when the impact stress increased so quickly that damage zones formed at the bar/ specimen contact areas first. Cracks initiate from the damage zone rather than the specimen centre, as shown in Fig. 10d. This can also be explained by the possibility that the high force acceleration from the input bar increases the friction between the bar and the specimen. Then, the local friction affects the stress distribution of the specimen and leads to premature failure at the contact zone of the bar/specimen. The presence of the foregoing cracks far from the disc centre affects the stress distribution and deformability of the specimen, so that a crushed strap forms, rather than a central split (Lanaro et al. 2009; Markides et al. 2010; Markides and Kourkoulis 2013). As the crack does not initiate from the specimen centre, the results of this type of failure should be avoided for strength analysis.

\section{Conclusions}

This work has explored the use of coupled-load equipment to investigate the tensile behaviour of rocks under coupled static and dynamic loads simultaneously. Theoretical and experimental analyses have shown that stress waves with an abruptly rising front like a stress pulse and rectangular waves are unsuitable for rock tests, whereas stress waves with a slowly rising front proved to be excellent. The central crack initiation and stress equilibrium in specimens have been verified for the coupled-load tests with the help of a high-speed camera and strain gauges on the specimens' surfaces.

The test results show that the tensile strength of granite under coupled loads decreases as the axial static pre-stresses increase. This is meaningful to underground engineering design and construction. Considering the example of mining, mineral excavation is usually conducted by blasting. When there is higher ground stress, less explosive might be needed in order to excavate the same volume of ore rock. On the other hand, the results imply that supporting structures such as rock pillars might be more vulnerable to dynamic loads when the working faces are at greater depth, where the rock endures higher ground stresses.

In addition, the study shows the usefulness of high-speed cameras in monitoring crack initiation and the failure 
patterns of specimens. Traditional recognition of failure patterns by post-test collection of broken pieces of sample might be erroneous. The true failure pattern of disc specimens from a valid Brazilian test should be a diametrical split with cracks neatly cutting through the centre of the specimen.

Acknowledgments The work reported here was supported by financial grants from the National Natural Science Foundation of China $(50904079,51274254)$ and the Program for New Century Excellent Talents in University (NCET-11-0528). The authors wish to acknowledge these financial contributions and their appreciation of the organisations for supporting this basic research. Also, the authors express their acknowledgements to Professor J. Zhao at Eccole Polytechnique Fédérale de Lausanne (EPFL) for his help in improving the paper.

\section{References}

ASTM International (2008) D3967-08: standard test method for splitting tensile strength of intact rock core specimens. ASTM International, West Conshohocken

Barla G, Innaurato N (1973) Indirect tensile testing of anisotropic rocks. Rock Mech 5:215-230

Berenbaum R, Brodie I (1959) Measurement of the tensile strength of brittle materials. Br J Appl Phys 10(6):281-287

Bieniawski ZT, Hawkes I (1978) Suggested methods for determining tensile strength of rock materials. Int J Rock Mech Min Sci Geomech Abstr 15(3):99-103

Cai M, Kaiser PK (2004) Numerical simulation of the Brazilian test and the tensile strength of anisotropic rocks and rocks with preexisting cracks. Int J Rock Mech Min Sci 41:478-483

Claesson J, Bohloli B (2002) Brazilian test: stress field and tensile strength of anisotropic rocks using an analytical solution. Int $\mathbf{J}$ Rock Mech Min Sci 39(8):991-1004

Dai F, Xia K (2010) Loading rate dependence of tensile strength anisotropy of Barre granite. Pure Appl Geophys 167(11):1419-1432

Dai F, Huang S, Xia K, Tan Z (2010) Some fundamental issues in dynamic compression and tension tests of rocks using split Hopkinson pressure bar. Rock Mech Rock Eng 43(6):657-666

Fairhurst C (1964) On the validity of the 'Brazilian' test for brittle materials. Int J Rock Mech Min Sci Geomech Abstr 1:535-546

Frantz CE, Follansbee PS, Wright WJ (1984) New experimental techniques with the split Hopkinson pressure bar. In: Proceedings 8th International Conference on High Energy Rate Fabrication, San Antonio, Texas, June 1984, pp 17-21

Frew DJ, Forrestal MJ, Chen W (2002) Pulse shaping techniques for testing brittle materials with a split Hopkinson pressure bar. Exp Mech 42(1):93-106

Hondros G (1959) The evaluation of Poisson's ratio and the modulus of materials of a low tensile resistance by the Brazilian (indirect tensile) test with particular reference to concrete. Aust J Appl Sci 10:243-268

Hudson JA, Brown ET, Rummel F (1972) The controlled failure of rock discs and rings loaded in diametral compression. Int J Rock Mech Min Sci Geomech Abstr 9(2):241-248

ISRM (1978) Suggested methods for determining tensile strength of rock materials. Int J Rock Mech Min Sci Geomech Abstr 15(3):99-103

Lanaro F, Sato T, Stephansson O (2009) Microcrack modelling of Brazilian tensile tests with the boundary element method. Int $\mathbf{J}$ Rock Mech Min Sci 46:450-461

Lavrov A, Vervoort A (2002) Theoretical treatment of tangential loading effects on the Brazilian test stress distribution. Int J Rock Mech Min Sci 39:275-283
Li D, Wong LNY (2013) The Brazilian disc test for rock mechanics applications: review and new insights. Rock Mech Rock Eng 46(2):269-287

Li XB, Zhou ZL, Lok TS, Hong L, Yin TB (2008) Innovative testing technique of rock subjected to coupled static and dynamic loads. Int J Rock Mech Min Sci 45(5):739-748

Li XB, Zhou ZL, Hong L, Yin TB (2009) Large diameter SHPB tests with a special shaped striker. ISRM News J 12:76-79

Li XB, Zhou ZL, Liu DS, Zou Y, Yin TB (2011) Wave shaping by special shaped striker in SHPB tests. In: Zhou Y, Zhao J (eds) Advances in rock dynamics and applications. CRC Press, Taylor \& Francis Group, Boca Raton, pp 105-124

Markides ChF, Kourkoulis SK (2012) The stress field in a standardized Brazilian disc: the influence of the loading type acting on the actual contact length. Rock Mech Rock Eng 45:145-158

Markides ChF, Kourkoulis SK (2013) Naturally accepted boundary conditions for the Brazilian disc test and the corresponding stress field. Rock Mech Rock Eng. doi:10.1007/s00603-012-0351-x

Markides ChF, Pazis DN, Kourkoulis SK (2010) Closed full-field solutions for stresses and displacements in the Brazilian disk under distributed radial load. Int J Rock Mech Mining Sci 47:227-237

Markides ChF, Pazis DN, Kourkoulis SK (2011) Influence of friction on the stress field of the Brazilian tensile test. Rock Mech Rock Eng 44:113-119

Markides ChF, Pazis DN, Kourkoulis SK (2012) The Brazilian disc under non-uniform distribution of radial pressure and friction. Int J Rock Mech Min Sci 50:47-55

Mellor M, Hawkes I (1971) Measurement of tensile strength by diametral compression of discs and annuli. Eng Geol 5:173-225

Pomeroy CD, Morgans WTA (1956) The tensile strength of coal. Br J Appl Phys 7:243-246

Rinehart JS (1975) Stress transients in solids. HyperDynamics, Santa $\mathrm{Fe}$

Wang QZ, Jia XM, Kou SQ, Zhang ZX, Lindqvist PA (2004) The flattened Brazilian disc specimen used for testing elastic modulus, tensile strength and fracture toughness of brittle rocks: analytical and numerical results. Int J Rock Mech Min Sci 41:245-253

Wang QZ, Li W, Song XL (2006) A method for testing dynamic tensile strength and elastic modulus of rock materials using SHPB. Pure Appl Geophys 163(5-6):1091-1100

Zhao J, Li HB (2000) Experimental determination of dynamic tensile properties of a granite. Int J Rock Mech Min Sci 37(5):861-866

Zhou ZL, Ma GW, Li XB (2007) Dynamic Brazilian splitting and spalling tests for granite. In: Proceedings of the 11th ISRM Congress on Rock Mechanics, Lisbon, Portugal, July 2007. Taylor \& Francis, London, pp 1127-1130

Zhou ZL, Li XB, Ye ZY, Liu KW (2010) Obtaining constitutive relationship for rate-dependent rock in SHPB tests. Rock Mech Rock Eng 43(6):697-706

Zhou ZL, Hong L, Li QY, Liu ZX (2011a) Calibration of SHPB system with special shape striker. J Central South Univ Technol 18(4):1139-1143

Zhou ZL, Li XB, Liu AH, Zou Y (2011b) Stress uniformity of split Hopkinson pressure bar under half-sine wave loads. Int J Rock Mech Min Sci 48(4):697-701

Zhou YX, Xia K, Li XB, Li HB, Ma GW, Zhao J, Zhou ZL, Dai F (2012) Suggested methods for determining the dynamic strength parameters and mode-I fracture toughness of rock materials. Int J Rock Mech Min Sci 49:105-112

Zhu WC, Tang CA (2006) Numerical simulation of Brazilian disk rock failure under static and dynamic loading. Int $\mathrm{J}$ Rock Mech Min Sci 43(2):236-252 